\title{
ARTHROGRYPOSIS MULTIPLEX CONGENITA: A RARE ASSOCIATION OF INFANT OF DIABETIC MOTHER
}

Pradipprava Paria ${ }^{1}$, Ramesh Chandra Halder ${ }^{2}$, Sibarjun Ghosh ${ }^{3}$

\section{HOW TO CITE THIS ARTICLE:}

Pradipprava Paria, Ramesh Chandra Halder, Sibarjun Ghosh. "Arthrogryposis Multiplex Congenita: A Rare Association of Infant of Diabetic Mother". Journal of Evolution of Medical and Dental Sciences 2015;

Vol. 4, Issue 72, September 07; Page: 12610-12613, DOI: 10.14260/jemds/2015/1816

ABSTRACT: Arthrogryposis multiplex congenita is a condition with non-progressive, multiple joint contractures present at birth. The major cause of arthrogryposis is fetal akinesia. There may be other causes like genetic influences, neurogenic, muscle and connective tissue abnormalities or maternal disorders. Management is usually conservative. Here we report a rare case of arthrogryposis in infant of diabetic mother with multiple congenital anomalies.

KEYWORDS: Infant of diabetic mother, Arthrogryposis, Other congenital anomalies, Lower limb.

INTRODUCTION: Arthrogryposis multiplex congenita, is a congenital anomaly in the newborn involving multiple curved joints. Children born with one or more joint contractures have abnormal fibrosis of the muscle tissue causing muscle shortening leading to restriction of passive extension and flexion in the affected joint or joints. ${ }^{1}$ It is well known that, infants of diabetic mother (IDM) are at an increased risk of morbidity and mortality related to the respiratory distress, growth abnormalities, hyperviscosity, hypoglycemia and congenital malformations like arthrogryposis multiplex congenita along with central nervous system, renal, cardiovascular, and gastrointestinal system anomalies.2,3 Here we report a neonate who was born to mother affected with type 2 diabetes had arthrogryposis with multiple congenital anomalies.

CASE REPORT: A female newborn of a second gravida mother was delivered vaginally at 38 weeks of gestation. There was no history of consanguinity. Mother was suffering from Type 2 diabetes and was on controlled with insulin injection. Her HbA1c at ninth month of gestation was 6.7. HIV \& VDRL serology were normal. No complication was there in her previous child birth. The birth weight of this baby was $2.9 \mathrm{~kg}$, head circumference $33 \mathrm{~cm}$ and length was $45 \mathrm{~cm}$. On physical examination, the infant had hairy pinna with low set ears. Anterior fontanel was open. Cardiovascular and respiratory system did not reveal any abnormality.

Liver was palpable $2 \mathrm{~cm}$ below right costal margin but spleen was not palpable. Omphalocele minor was present. She had also bladder extrophy and right sided inguinal hernia. External genitalia and anal opening was in normal position. Both the lower limbs were arthrogrypotic characterized by fixed-flexion deformity of the hip, flexion of the knees with pterygium formation, dorsi-flexed ankles along with slight eqiunovarus feet (Fig. 1). Bilateral congenital hip dislocation with restriction of the lower limb movement was present. No history of similar illness was found in the family. Based on these skeletal abnormalities, she was diagnosed as arthrogryposis. USG abdomen and brain did not reveal any abnormality. We conservatively managed the neonate and discharged after 7 days and advised to be followed up in high risk clinic and also in our orthopedics and urology OPD. 


\section{CASE REPORT}

Figure 1 and 2: Arthrogryposis multiplex congenita with omphalocele minor, Bladder exstrophyand inguinal hernia

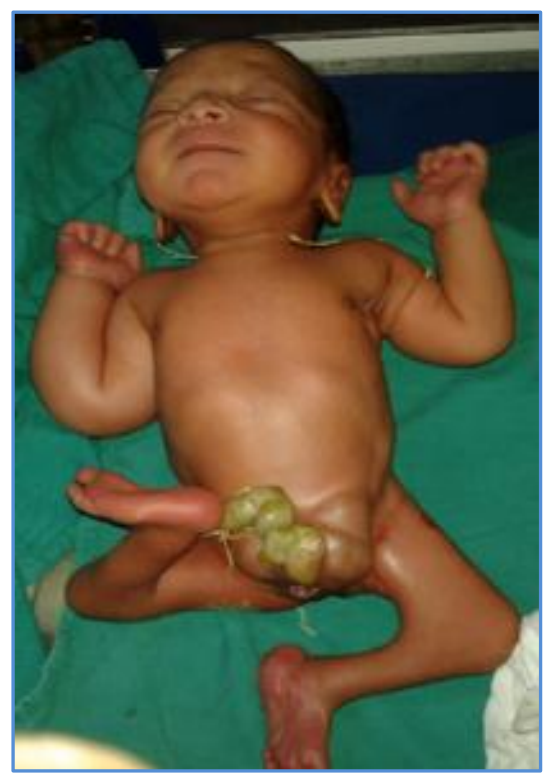

Fig. 1

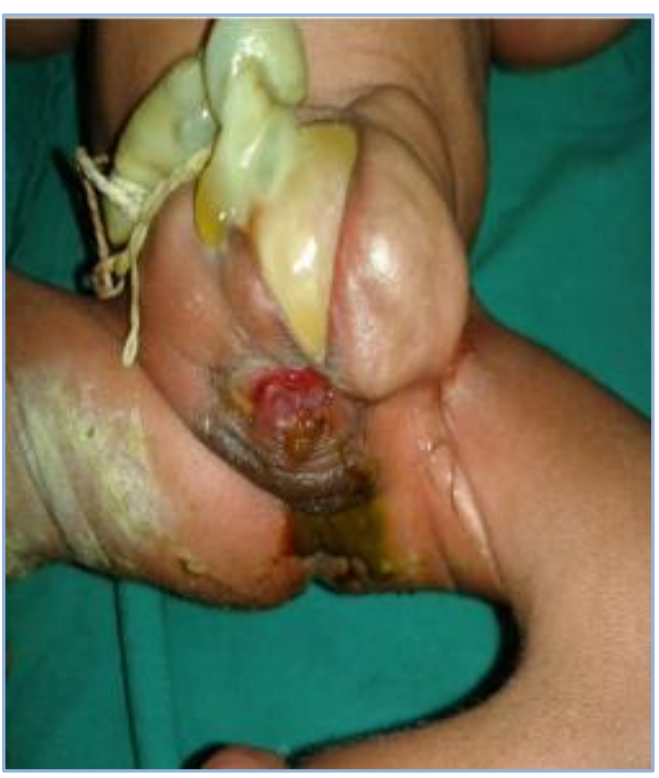

Fig. 2

DISCUSSION: The incidence of congenital anomalies is increased in IDM. Common anomalies are cardiac malformations and lumbosacral agenesis. Other anomalies include neural tube defect, hydronephrosis, renal agenesis, duodenal or anorectal atresia, situs inversus and holoprosencephaly.

Congenital anomalies in IDM babies correlate well with poor metabolic control during the periconception and organogenesis periods and may be due to hyperglycemia induced teratogenesis. ${ }^{4}$

The mechanism by which hyperglycemia influences embryonic development is controversial, but associated reduced arachidonic acid and myoinositol levels and accumulation of sorbitol and trace metals in the conceptus have been reported. 4,5

Arthrogryposis multiplex congenita (AMC), a congenital anomaly though common, it's association with maternal diabetes is very rare. After extensive search, only two reported cases was found. It is characterized by non-progressive, multiple joint contractures present at birth. It has been divided into three groups: amyoplasia, distal arthrogryposis, and syndromic. Amyoplasia is characterized by severe joint contractures and muscle weakness. Distal arthrogryposis mainly involves the hands and feet and arthrogryposis with a primary involvement of neurological or muscular system belong to the syndromic group. ${ }^{6}$

It occurs 1 in 10,000 live birth. ${ }^{4}$ Almost every joint in a patient with arthrogryposis is affected, because in $84 \%$ all limbs are involved, in $11 \%$ only the legs and in $4 \%$ only the arms are involved. ${ }^{7}$ In our case, only the lower limbs are affected. Deformities tend to be symmetric with preservation of normal sensation. Contractures are more prominent in distal joints than proximal and the trunk is frequently spared. Other associated deformities include scoliosis, genital deformities, hernia (Inguinal, umbilical) and gastroschisis. Association of omphalocele minor, bladder exstrophy and also inguinal hernia as in our case, was not reported earlier. 
AMC is multifactorial in etiology. The major extrinsic cause for the arthrogyrposis is fetal akinesia $^{1}$ due to structural abnormality of the uterus, oligohydramnios, increased intrauterine pressure, breech presentation and defects in the fetal blood supply. Other causes could be viral infections and Myasthenia gravis of the mother.

Intrinsic causes are genetic disorder due to single gene, along with mitochondrial and chromosomal defect. It may also be due to muscles or connective tissue disorder or neurological abnormalities.6,7 Clinical examination remains the best modality for establishing the diagnosis. X-rays of the joints demonstrate the bony abnormalities.8,9 Ultrasound, CT and MRI scans help in further delineation.

Management in a case of arthrogryposis should be a coordinated and team approach. Goal is lower-limb alignment and establishment of stability for ambulation and self-care for upper-limb function. Early physiotherapy and stretching is used to improve the range of motion of contracted joint and surrounding tissues. ${ }^{10}$ Serial casting with weekly changes of cast along with physiotherapy and gentle manipulation are most useful mode of therapy.11 in some cases, surgery may be needed to correct soft tissue contractures and joint deformities. It can also reduce and stabilize dislocated hips, correct foot deformities and minimize spinal deformities. ${ }^{12}$

\section{REFERENCES:}

1. Kalampokas, Emmanouil; Kalampokas, Theodoros; Sofoudis, Chrisostomos; Deligeoroglou, Efthymios; Botsis, Dimitrios (2012). "Diagnosing Arthrogryposis Multiplex Congenita: A Review". ISRN Obstetrics and Gynecology 2012:1.

2. Cordero L, Landon MB. Infant of the diabeticmother.ClinPerinatol1993; 20: 635-48.

3. Nold JL, Georgieff MK. Infant of diabetic mothers. Pediatric Clinics of North America 2004; 51:619- 637.

4. Stoll BJ. The endocrine system. In Behrman RE, Kleigman RM, Jenson HB, Stanton BF editors. Nelson Textbook of Pediatrics.18th ed. Prism Books. WB Saunders, Philadelphia, 2007; pg. 78385.

5. Gordon N. Arthrogryposis multiplex congenital. Brain Dev1998; 20(7):507-11.

6. Bamshad, Michael; Van Heest, AE; Pleasure, D (2009)."Arthrogryposis: A Review and Update". The Journal of Bone and Joint Surgery (American) 91 (Suppl 4): 40-6.

7. Bevan, Wesley P.; Hall, Judith G.; Bamshad, Micheal; Staheli, Lynn T.; Jaffe, Kenneth M.; Song, Kit (2007). "Arthrogryposis Multiplex Congenita (Amyoplasia)".Journal of Pediatric Orthopaedics 27 (5): 594-600.

8. Hosalkar HS, Drummond DS. Arthrogryposis. In Behrman RE, Kleigman RM, Jenson HB, Stanton BF editors. Nelson Textbook of Pediatrics. 18th ed. Prism Books. WB Saunders, Philadelphia, 2007; pg. 2829-31.

9. Hall JG. Genetic aspect of arthrogryposis. Clin Orthop Rel Res 1985; 84:44-53.

10. Bernstein RM. Arthrogryposis and amyoplasia. JAm AcadOrthopSurg2002; 10(6):417-424.

11. Smith DW, Drennan JC; Arthrogryposis wrist deformities: results of infantile serial casting. J Pediatr Orthop. 2002 Jan-Feb; 22(1):44-7.

12. Bevan WP, Hall JG, Bamshad M, et al. Arthrogryposis multiplex congenita (Amyoplasia): an orthopaedic perspective. J Pediatr Orthop. 2007; 27:594-600. 


\section{CASE REPORT}

\section{AUTHORS:}

1. Pradipprava Paria

2. Ramesh Chandra Halder

3. Sibarjun Ghosh

\section{PARTICULARS OF CONTRIBUTORS:}

1. RMO-Cum-Clinical Tutor, Department of Pediatrics, R. G. Kar Medical College, Kolkata.

2. RMO-Cum-Clinical Tutor, Department of Pediatrics, R. G. Kar Medical College, Kolkata.

3. Professor and HOD, Department of Pediatrics, R. G. Kar Medical College, Kolkata.

FINANCIAL OR OTHER COMPETING INTERESTS: None

\section{NAME ADDRESS EMAIL ID OF THE} CORRESPONDING AUTHOR:

Pradipprava Paria,

R. G. Kar Medical College,

1, Khudiram Bose Sarani,

Kolkata.

E-mail: drpradip83@gmail.com

Date of Submission: 20/08/2015.

Date of Peer Review: 21/08/2015.

Date of Acceptance: 02/09/2015.

Date of Publishing: 07/09/2015. 